\begin{tabular}{|c|c|}
\hline Title & Solvothermal syntheses of semiconductor photocataly sts of ultra high activities \\
\hline Author(s) & $\begin{array}{l}\text { Kominami, Hiroshi; Kato, Jun-ichi; Murakami, Shin-ya; Ishii, Y oshinori; Kohno, Masaaki; Y abutani, Kei-ichi; } \\
\text { Y amamoto, T akuhei; Kera, Y oshiya; Inoue, Masashi; Inui, Tomoyuki; Ohtani, Bunsho }\end{array}$ \\
\hline Citation & $\begin{array}{l}\text { Cataly sis T oday, 84(3-4), 181-189 } \\
\text { https://doi.org/10.1016/S0920-5861(03)00272-4 }\end{array}$ \\
\hline Issue Date & $2003-09-15$ \\
\hline Doc URL & http:/hdl.handle.net/2115/17127 \\
\hline Tyре & article (author version) \\
\hline Note & 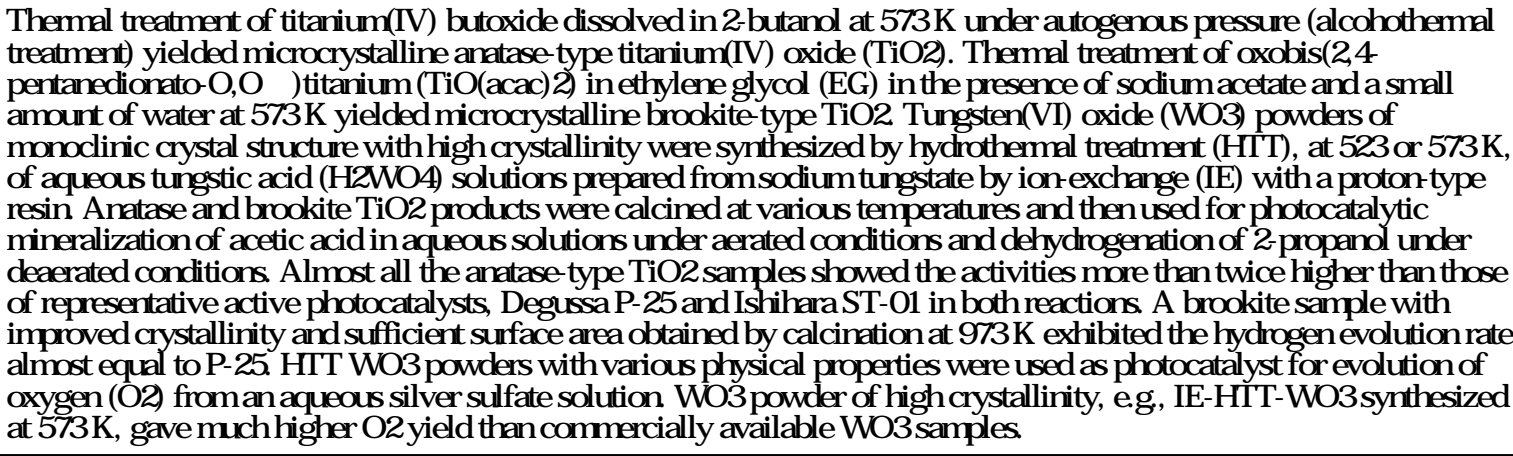 \\
\hline Note(URL) & http://www.elsevier.com/wps/find/מournaldescription.cws_home/500857/description \\
\hline File Information & CT84-3-4.pdf \\
\hline
\end{tabular}

Instructions for use 


\title{
Solvothermal Syntheses of Semiconductor Photocatalysts of Ultra-high Activities
}

Hiroshi Kominami, Jun-ichi Kato, Shin-ya Murakami, Yoshinori Ishii, Masaaki Kohno, Kei-ichi Yabutani, Takuhei Yamamoto, Yoshiya Kera, Masashi Inoue,, Tomoyuki Inui, ${ }^{a}$ Bunsho Ohtani ${ }^{\mathrm{b}}$

Department of Applied Chemistry, Faculty of Science and Engineering, Kinki University, Kowakae, Higashiosaka, Osaka 577-8502, Japan

${ }^{\mathrm{a}}$ Department of Energy and Hydrocarbon Chemistry, Graduate School of Engineering, Kyoto University, Yoshida, Kyoto 606-8501, Japan

${ }^{\mathrm{b} C}$ Catalysis Research Center, Hokkaido University, Sapporo 060-0811, Japan.

\begin{abstract}
Thermal treatment of titanium(IV) butoxide dissolved in 2-butanol at $573 \mathrm{~K}$ under autogenous pressure (alcohothermal treatment) yielded microcrystalline anatase-type titanium(IV) oxide $\left(\mathrm{TiO}_{2}\right)$. Thermal treatment of oxobis(2,4-pentanedionato-O,O')titanium ( $\left.\mathrm{TiO}(\mathrm{acac})_{2}\right)$ in ethylene glycol (EG) in the presence of sodium acetate and a small amount of water at $573 \mathrm{~K}$ yielded microcrystalline brookite-type $\mathrm{TiO}_{2}$. Tungsten(VI) oxide $\left(\mathrm{WO}_{3}\right)$ powders of monoclinic crystal structure with high crystallinity were synthesized by hydrothermal treatment (HTT), at 523 or $573 \mathrm{~K}$, of aqueous tungstic acid $\left(\mathrm{H}_{2} \mathrm{WO}_{4}\right)$ solutions prepared from sodium tungstate by ion-exchange (IE) with a proton-type resin. Anatase and brookite $\mathrm{TiO}_{2}$ products were calcined at various temperatures and then used for photocatalytic mineralization of acetic acid in aqueous solutions under aerated conditions and dehydrogenation of 2-propanol under deaerated conditions. Almost all the anatase-type $\mathrm{TiO}_{2}$ samples showed the activities more than twice higher than those of representative active
\end{abstract}


photocatalysts, Degussa P-25 and Ishihara ST-01 in both reactions. A brookite sample with improved crystallinity and sufficient surface area obtained by calcination at $973 \mathrm{~K}$ exhibited the hydrogen evolution rate almost equal to P-25. $\mathrm{HTT} \mathrm{WO}_{3}$ powders with various physical properties were used as photocatalyst for evolution of oxygen $\left(\mathrm{O}_{2}\right)$ from an aqueous silver sulfate solution. $\quad \mathrm{WO}_{3}$ powder of high crystallinity, e.g., IE-HTT- $\mathrm{WO}_{3}$ synthesized at $573 \mathrm{~K}$, gave much higher $\mathrm{O}_{2}$ yield than commercially-available $\mathrm{WO}_{3}$ samples

\section{INTRODUCTION}

Titanium(IV) oxide $\left(\mathrm{TiO}_{2}\right)$ has attracted much attention mainly in expectation of being applied to environmental photocatalytic processes such as deodorization, prevention of stains, sterilization [1], and removal of pollutants from air and water [2-4]. For the realization of their practical application, development of highly active $\mathrm{TiO}_{2}$ photocatalyst is keenly desired. Based on the kinetic investigation of photocatalytic reactions, we have pointed out that $\mathrm{TiO}_{2}$ particles having both large surface area and high crystallinity must exhibit higher photocatalytic activity [5]. The former property should increase the amount of surface-adsorbed substrate(s) to enhance the capture of photogenerated electron $\left(\mathrm{e}^{-}\right)$and positive hole $\left(\mathrm{h}^{+}\right)$, and the latter, i.e., less defects acting as the recombination center, should suppress mutual $\mathrm{e}^{-}-\mathrm{h}^{+}$recombination. However, it is generally difficult to satisfy these two properties by representative methods such as precipitation and sol-gel technique.

Among $\mathrm{TiO}_{2}$ there exist three crystal phases; anatase, rutile and brookite. The anatase and rutile phases are well known and many studies on their synthesis, photocatalysis and application for catalyst supports have been reported. On the other hand, only a few studies on the synthesis of brookite-type $\mathrm{TiO}_{2}$ have been examined [6,7]. To our knowledge, there is only one paper in which synthesized brookite $\mathrm{TiO}_{2}$ was successfully used as catalyst materials [8]. Difficulty to prepare brookite having both high purity and large surface is 
probably one of the reasons for limited application of brookite $\mathrm{TiO}_{2}$ as catalyst support and photocatalyst.

Tungsten(VI) oxide $\left(\mathrm{WO}_{3}\right)$, whose band gap energy has been estimated to be $2.5 \mathrm{eV}$, has the potential ability to photocatalyze under irradiation of visible light of wavelength $<$ ca. 500 nm. Actually, visible light-induced action of oxidizing water has been reported using $\mathrm{WO}_{3}$ powder and iron(III) ions (or silver ions) as the electron acceptor [9-12]. However, commercially available $\mathrm{WO}_{3}$ powders have been used in these studies, and the properties of $\mathrm{WO}_{3}$ suitable for the photocatalytic activity for oxygen $\left(\mathrm{O}_{2}\right)$ evolution have not been clarified. The photocatalytic $\mathrm{O}_{2}$ evolution, a half part of stoichiometric water decomposition, seem still ambiguous in its mechanism and, thereby, investigations on the visible light-induced evolution on $\mathrm{WO}_{3}$ are needed for, e.g, development of solar energy conversion systems.

In this study, we applied solvothermal method to synthesize semiconductor photocatalysts of high activities. When water $\left(\mathrm{H}_{2} \mathrm{O}\right)$ is used as the synthesis medium, the method is called hydrothermal method [13]. Similarly, alcohothermal means solvothermal in alcohol [14]. Here, we show solvothermal syntheses of three photocatalysts, alcohothermal synthesis of anatase-type $\mathrm{TiO}_{2}$, solvothermal synthesis of brookite-type $\mathrm{TiO}_{2}$ in glycol- $\mathrm{H}_{2} \mathrm{O}$ medium, and hydrothermal synthesis of $\mathrm{WO}_{3}$.

\section{EXPERIMENTAL}

\subsection{Alcohothermal synthesis of anatase-type $\mathrm{TiO}_{2}$}

Titanium(IV) alkoxides, $10 \mathrm{~g}$, was dissolved in a $70 \mathrm{~cm}^{3}$ portion of an alcohol in a test tube which was then set in a $200-\mathrm{cm}^{3}$ autoclave (Figure 1). An additional $30 \mathrm{~cm}^{3}$ of the alcohol was placed in the gap between the test tube and the autoclave wall. The autoclave was thoroughly purged with nitrogen, heated to desired temperature (523-573 K) at a rate of $2.5 \mathrm{~K} \mathrm{~min}^{-1}$, and kept at that temperature for $2 \mathrm{~h}$. After the autoclave treatment, the 
resulting powders were washed repeatedly with acetone and dried in air.

\subsection{Synthesis of brookite-type $\mathrm{TiO}_{2}$ in glycol-water medium}

Typical synthesis procedure is as follows

Oxobis(2,4-pentanedionato-O,O')titanium (TiO(acac)2, 0.019 mol) (Tokyo Kasei) and sodium acetate $(0.038 \mathrm{~mol})$ (Kanto Chemical) were added to $70 \mathrm{~cm}^{3}$ of ethylene glycol (EG) (Kanto Chemical) in a test tube, which was then set in $200 \mathrm{~cm}^{3}$ autoclave. In the gap between the test tube and the autoclave wall, $5 \mathrm{~cm}^{3}$ of water was added. At this point, water contacted neither $\mathrm{TiO}(\mathrm{acac})_{2}$ nor EG. The autoclave was purged with nitrogen, heated at $573 \mathrm{~K}$ at a rate of $2.5 \mathrm{~K} \mathrm{~min}^{-1}$, and held at that temperature for $2 \mathrm{~h}$. During the reaction, water was vaporized and dissolved in EG. The products were washed first with acetone and then with water repeatedly under sonication, and dried at room temperature.

\subsection{Hydrothermal synthesis of $\mathrm{WO}_{3}$}

Aqueous $\mathrm{H}_{2} \mathrm{WO}_{4}$ solutions were prepared by the cation-exchange method with a strongly acidic ion-exchange (IE) resin in its proton $\left(\mathrm{H}^{+}\right)$form [16]. Prior to IE, diluted hydrochloric acid $(\mathrm{HCl})\left(0.1 \mathrm{~mol} \mathrm{dm}^{-3}, 240 \mathrm{~cm}^{3}\right)$ was added to the resin (Organo, Amberlite IR120B NA, $30 \mathrm{~cm}^{3}$ ) packed in a glass column to make it in the $\mathrm{H}^{+}$form and then the resin was washed with distillated water until chloride ions were no longer detected in the eluent. An aqueous solution of $\mathrm{NaWO}_{4}$ (Wako; $0.39 \mathrm{~mol} \mathrm{dm}{ }^{-3}, 37.5 \mathrm{~cm}^{3}$ ) was loaded on the column and $\mathrm{H}_{2} \mathrm{WO}_{4}$ was recovered from the column by elution with distilled water $\left(37.5 \mathrm{~cm}^{3}\right)$. The

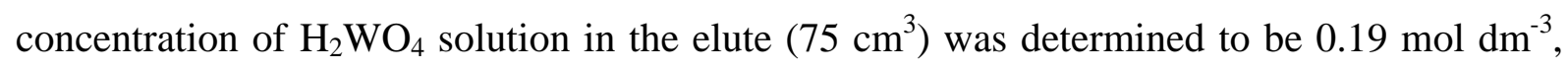
which corresponded to $98 \%$ recovery.

The clear $\mathrm{H}_{2} \mathrm{WO}_{4}$ solution in the glass tube was set in a $300-\mathrm{cm}^{3}$ autoclave. The gap between the tube and inside wall of the autoclave was filled with $25 \mathrm{~cm}^{3}$ of water. The 
autoclave was thoroughly purged with nitrogen, heated to a desired temperature (473-573 K) at a rate of $2.5 \mathrm{~K} \mathrm{~min}^{-1}$, and kept at that temperature for $2 \mathrm{~h}$. After the heating, the resulting powder was washed repeatedly with acetone and dried in air at room temperature. Hydrothermal treatment (HTT) of solid $\mathrm{H}_{2} \mathrm{WO}_{4}$ with tungstite structure (supplied as "tungstic acid” from Kanto Chemicals) was also carried out under conditions similar to those described above.

\subsection{Calcination and characterization}

Calcination of the samples was carried out in a box furnace; the sample in a combustion boat was heated to the desired temperature at a rate of $10 \mathrm{~K} \mathrm{~min}^{-1}$ and kept at that temperature for $1 \mathrm{~h}$. Powder X-ray diffraction (XRD) with $\mathrm{CuK} \alpha$ radiation was recorded on a Rigaku RINT 2500 diffractometer equipped with a carbon monochromator. Thermogravimetry (TG) and differential thermal analysis (DTA) were performed using a Rigaku TG-8120 under a flow of air at $100 \mathrm{~cm}^{3} \mathrm{~min}^{-1}$. Morphology of the powders was observed using a JEOL 5200 scanning electron microscope (SEM) and a JEOL JEM-3010 transmission electron microscope (TEM). Diffuse reflectance spectra were obtained by a Shimadzu UV-2400 UV-vis spectrometer equipped with a diffuse reflectance measurement unit (ISR-2000) and recorded after Kubelka-Munk analysis. Specific surface area was determined by the BET single-point method using nitrogen uptake at $77 \mathrm{~K}$.

$$
\begin{gathered}
\mathrm{CH}_{3} \mathrm{COOH}+2 \mathrm{O}_{2} \rightarrow 2 \mathrm{CO}_{2}+2 \mathrm{H}_{2} \mathrm{O} \\
\mathrm{CH}_{3} \mathrm{CH}(\mathrm{OH}) \mathrm{CH}_{3} \rightarrow \mathrm{H}_{2}+\mathrm{CH}_{3} \mathrm{COCH}_{3} \\
4 \mathrm{Ag}^{+}+2 \mathrm{H}_{2} \mathrm{O} \rightarrow \mathrm{O}_{2}+\mathrm{Ag}+4 \mathrm{H}^{+}
\end{gathered}
$$

\subsection{Photoirradiation and product analyses}


(A) Photocatalytic reaction in an aqueous $\mathrm{AcOH}$ solution: bare $\mathrm{TiO}_{2}$ powder $(50 \mathrm{mg}$ ) was suspended in an AcOH solution $\left(175 \mu \mathrm{mol}, 5.0 \mathrm{~cm}^{3}\right)$ [17]. $\quad$ (B) Photocatalytic reaction in an aqueous 2-PrOH solution: $\mathrm{Pt}(0.1 \mathrm{wt} \%)-\mathrm{TiO}_{2}$ powder $(50 \mathrm{mg})$ was suspended in a 2-PrOH solution (500 $\left.\mu \mathrm{mol}, 5.0 \mathrm{~cm}^{3}\right)$ [18]. $\quad$ (C) Photocatalytic reaction in an aqueous silver sulfate $\left(\mathrm{Ag}_{2} \mathrm{SO}_{4}\right)$ solution: bare $\mathrm{TiO}_{2}$ powder $(50 \mathrm{mg})$ was suspended in an $\mathrm{Ag}_{2} \mathrm{SO}_{4}$ solution (125 $\left.\mu \mathrm{mol}, 5.0 \mathrm{~cm}^{3}\right)$ [19]. The reaction of (A) was carried out in reaction tubes (18 $\mathrm{mm}$ in diameter and $180 \mathrm{~mm}$ in length, transparent for light with a wavelength of $>300 \mathrm{~nm}$ ) under aerated conditions, while those of (B) and (C) was carried out under an Ar atmosphere. The suspension was stirred $(1000 \mathrm{rpm})$ at $298 \mathrm{~K}$ by using a magnet bar. After the irradiation, the amounts of carbon dioxide $\left(\mathrm{CO}_{2}\right)$, hydrogen $\left(\mathrm{H}_{2}\right)$ and $\mathrm{O}_{2}$ in the gas phase of reaction mixtures were measured using a Shimadzu GC-8A gas chromatograph equipped with Porapak QS $\left(\mathrm{CO}_{2}\right)$ and MS-5A $\left(\mathrm{H}_{2}\right.$ and $\left.\mathrm{O}_{2}\right)$ columns. The amounts of 2-PrOH and acetone were analyzed using a Shimadzu GC-8A gas chromatograph equipped with an FID and a column packed with PEG20M. Deposited Ag was analyzed by inductively coupled plasma emission spectroscopy (ICP, Shimadzu ICPS-1000III) after dissolution with concentrated nitric acid $\left(\mathrm{HNO}_{3}\right)$.

\section{Results and Discussion}

\subsection{Characterization of $\mathrm{TiO}_{2}$ prepared by alcohothermal method}

An XRD pattern of the product prepared by alcohothermal treatment of titanium n-butoxide (TNB) in 2-butanol at $573 \mathrm{~K}$ is depicted in Figure 2(a), which shows that anatase [20] was formed without contamination of any other phases such as rutile or brookite. Addition of water to the supernatant after the autoclaving gave no precipitates, indicating that TNB was completely hydrolyzed during the thermal treatment. Judging from the fact that the treatment of TNB in toluene at the same temperature yielded no product, the source of 
water for the hydrolysis was that generated from 2-butanol. This sample possessed sufficient surface area of $63 \mathrm{~m}^{2} \mathrm{~g}^{-1}$ and the crystallite size of this sample was calculated to be $19 \mathrm{~nm}$ from the line-broadening of the 101 diffraction peak of anatase. TEM observation (Figure 3) revealed that the sample consisted of the agglomerates of primary particles of an average diameter of $20 \mathrm{~nm}$, which was in good agreement with the crystallite size estimated from the XRD pattern. Therefore, each particle observed in TEM should be a single anatase crystal. TG analysis revealed that this sample showed gradual weight loss of $2.42 \%$ from 373 to $1273 \mathrm{~K}$ and only a very weak exothermic peak at $560 \mathrm{~K}$ was observed in a DTA curve due to combustion of a small amount of remaining organic moieties. Absence of sharp exothermic peak due to crystallization of anatase at around 673-773 K suggests that the product contains a negligible amount of amorphous-like phase, which is well consistent with the results of XRD and TEM. When titanium isopropoxide (TIP) was dissolved in a mixed solvent of 7 vol\% 2-propanol in toluene, TIP was completely hydrolyzed to give anatase as observed in 100\% 2-propanol. The amount of water required for complete hydrolysis of TIP is calculated to be $0.14 \mathrm{~mol}$. Assuming that 2-propanol in toluene is completely dehydrated, the amount of water formed from the mixed solvent is estimated to be 0.064 mol, which is smaller than that necessary for the complete hydrolysis of TIP. Two possibilities might account for this; 2-propanol formed by hydrolysis of TIP was dehydrated to yield water which was then used for the hydrolysis, and/or water generated by dehydration of hydrated $\mathrm{TiO}_{2}$ was used again to hydrolyze TIP. In both processes water was recycled. In the present paper, the $\mathrm{TiO}_{2}$ sample prepared by alcohothermal method is called $\mathrm{THyCA}$

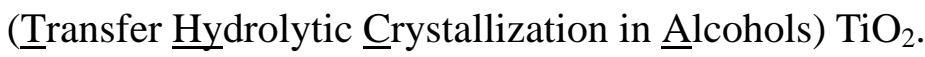

Effect of calcination on physical properties of $\mathrm{THyCA}-\mathrm{TiO}_{2}$ prepared in the TNB-2-butanol system is shown in Figure 4. Post-calcination at temperatures lower than $973 \mathrm{~K}$ reduced the BET surface area slightly. This is consistent with the result that the 
XRD pattern of the $\mathrm{TiO}_{2}$ sample calcined at $823 \mathrm{~K}$ was almost identical to that before calcination, as shown in Figure 2(b). Even after calcination at $973 \mathrm{~K}$, the $\mathrm{THyCA}^{-\mathrm{TiO}_{2}}$ was composed of small anatase crystallite of $26 \mathrm{~nm}$ diameter (Figure 2(c)) and still possessed sufficient surface area of $45 \mathrm{~m}^{2} \mathrm{~g}^{-1}$. Calcination at $1173 \mathrm{~K}$ induced partial transformation into the rutile, but the sample still predominantly consisted of the anatase crystallite (Figure 2(d)). The high thermal stability of $\mathrm{THyCA}-\mathrm{TiO}_{2}$ is interpreted by assuming that the as-prepared THyCA $\mathrm{TiO}_{2}$ consists of single crystals and contains negligible amount of amorphous-like phase to be crystallized into anatase and to induce sintering of crystallites upon calcination.

\subsection{Photocatalytic activities of $\mathrm{THyCA}^{-\mathrm{TiO}_{2}}$}

Figure 5 shows the effect of calcination on the $\mathrm{CO}_{2}$ evolution rate of $\mathrm{THyCA}-\mathrm{TiO}_{2}$ in photocatalytic mineralization of acetic acid. Uncalcined $\mathrm{THyCA}-\mathrm{TiO}_{2}$ exhibited the rate of $21.3 \mu \mathrm{mol} \mathrm{h}{ }^{-1}$ that was much larger than those of representative commercial $\mathrm{TiO}_{2}$, Degussa P-25 and Ishihara ST-01 (8.5 and $11.6 \mu \mathrm{mol} \mathrm{h}{ }^{-1}$ ), which have been known to show high photocatalytic activity. Since the $\mathrm{THyCA}-\mathrm{TiO}_{2}$ powders satisfied the basic requirements for active $\mathrm{TiO}_{2}$ photocatalyst, i.e., both large surface area and sufficient crystallinity, the present results can be reasonably accepted. An amorphous hydrated $\mathrm{TiO}_{2}$ of quite large surface area prepared by hydrolysis under atmospheric conditions showed negligible activity $\left(<1 \mu \mathrm{mol} \mathrm{h}{ }^{-1}\right)$, due to large recombination probability of photogenerated $\mathrm{e}^{-}$and $\mathrm{h}^{+}$at large number of surface defects. Calcination of $\mathrm{THyCA}^{-\mathrm{TiO}_{2}}$ powders decreased their photocatalytic activities, suggesting that surface area, i.e., adsorptibity to toward acetic acid, is decisive factor in this reaction system.

Effect of calcination on the $\mathrm{H}_{2}$ evolution rate of platinized $\mathrm{THyCA}^{-\mathrm{TiO}_{2}}$ in photocatalytic dehydrogenation of 2-propanol in aqueous suspension is shown in Figure 6. 
It should be noted that temperature dependency of the rate was different from that of mineralization of acetic acid. The rate increased with temperature until $973 \mathrm{~K}$ and sample obtained by calcination at that temperature exhibited a rate of $200 \mu \mathrm{mol} \mathrm{h}{ }^{-1}$, which was much higher than that of P-25 $\left(100 \mu \mathrm{mol} \mathrm{h}{ }^{-1}\right)$ as well as the mineralization system. This dependency suggests that balance of surface area and crystallinity, which control adsorptivity and $\mathrm{e}^{-}-\mathrm{h}^{+}$recombination probability, respectively, is important in hydrogen evolution system.

\subsection{Characterization and photocatalytic activities of brookite-type $\mathrm{TiO}_{2}$}

XRD pattern of the product is shown in Figure 7(a). All the XRD peaks of the product were assigned to brookite [21]. The crystallite size of this brookite sample was calculated to be $16 \mathrm{~nm}$ from the 121 diffraction peak using Scherrer equation. Due to the nano-crystalline property, this brookite sample had a large surface area of $78 \mathrm{~m}^{2} \mathrm{~g}^{-1}$. In the previous paper [15], Raman spectroscopy and TEM observation revealed that the product consisted of agglomerates of brookite nano-crystals without contamination of other phases, anatase and rutile. In the TG curve of the product, weight loss was observed at the range from 473 to $773 \mathrm{~K}$ and total weight loss up to $1273 \mathrm{~K}$ was $6 \%$. An exothermic peak was observed at $562 \mathrm{~K}$ in the DTA curve, which is attributed to combustion of organic moieties on the product. However, no DTA peak was observed in the high temperature region.

The brookite product was calcined at various temperatures and XRD patterns after calcination are shown in Figure 7(b)-(f). A very weak peak due to the rutile phase was observed after calcination at $823 \mathrm{~K}$. Peaks of brookite became sharper after calcination at $973 \mathrm{~K}$ and formation of rutile $\mathrm{TiO}_{2}$ was remarkable on calcination at $1173 \mathrm{~K}$. The anatase form was not observed in XRD pattern of any calcined samples, indicating that brookite directly transformed to the rutile phase. These results of XRD were consistent with those of Raman spectroscopy [15]. Calcination temperature-dependency of physical properties of 
the product is shown in Figure 8. Surface area of the sample gradually decreased with the elevation in calcination temperature while crystallite size increased, indicating that crystal growth of brookite occurred along with calcination and crystallinity of brookite sample was increased.

These brookite samples of various physical properties were platinized and then used for photocatalytic dehydrogenation of 2-propanol in aqueous suspensions. Effect of calcination on the $\mathrm{H}_{2}$ evolution rate is shown in Figure 9. The rate increased with temperature until 973 $\mathrm{K}$ and sample obtained by calcination at that temperature exhibited a rate of $104 \mu \mathrm{mol} \mathrm{h}{ }^{-1}$, which was almost similar to that of P-25 $\left(100 \mu \mathrm{mol} \mathrm{h} \mathrm{h}^{-1}\right)$. It should be noted that brookite-type $\mathrm{TiO}_{2}$ exhibited high photocatalytic activity if it possesses adequate physical properties. Severer calcination decreased the rate as was observed in $\mathrm{THyCA}-\mathrm{TiO}_{2}$ (Figure 5). This same dependency suggests that balance of surface area and crystallinity, which control adsorptivity and $\mathrm{e}^{-}-\mathrm{h}^{+}$recombination probability, respectively, is important in $\mathrm{H}_{2}$ evolution system independent of the crystal structure of $\mathrm{TiO}_{2}$.

\subsection{Photocatalytic activity of $\mathrm{WO}_{3}$ synthesized by hydrothermal method}

Figure 10 shows XRD patterns of the powders obtained by HTT at various temperatures of $\mathrm{H}_{2} \mathrm{WO}_{4}$ solutions. Hydrated $\mathrm{WO}_{3}\left(\mathrm{WO}_{3} \cdot 0.33 \mathrm{H}_{2} \mathrm{O}\right)$ [22] was obtained by HTT at $473 \mathrm{~K}$ (Figure 10(a)), while $\mathrm{WO}_{3}$ with a monoclinic structure [23] was obtained at $523 \mathrm{~K}\left(\mathrm{WO}_{3}-\mathrm{A}\right)$ (Figure $10(\mathrm{~b})$ ), suggesting that $\mathrm{WO}_{3}$ was produced via $\mathrm{WO}_{3} \bullet 0.33 \mathrm{H}_{2} \mathrm{O}$ during HTT. For $\mathrm{WO}_{3}-\mathrm{A}$, the yield of $\mathrm{WO}_{3}$ was estimated to be $94 \%$ on the basis of the molar amount of $\mathrm{H}_{2} \mathrm{WO}_{4}$ in the feed. Further increase in $\mathrm{T}_{\text {HTT }}$ up to $573 \mathrm{~K}$ and prolongation of HTT time at that temperature increased the crystallinity of $\mathrm{WO}_{3}$ products $\left(\mathrm{WO}_{3}-\mathrm{B}\right.$ and $-\mathrm{C}$, respectively) due to the higher solubility of tungsten species in water at higher $\mathrm{T}_{\text {HTT }}$ (Figures 10 (c) and (d)). As clearly shown in the XRD patterns, the intensities of 020, 200, 202, 220, 400, 402 
diffraction peaks in these products increased with $\mathrm{T}_{\mathrm{HTT}}$ up to $573 \mathrm{~K}$, indicating that the growth of $\mathrm{WO}_{3}$ crystallite proceeded toward $a$ and $b$ axes, especially the $a$ axis, under HTT conditions at $573 \mathrm{~K}$. SEM photographs of $\mathrm{WO}_{3} \cdot 0.33 \mathrm{H}_{2} \mathrm{O}, \mathrm{WO}_{3}-\mathrm{A}, \mathrm{WO}_{3}-\mathrm{B}$ and $\mathrm{WO}_{3}-\mathrm{C}$ samples are shown in Figure 11. The $\mathrm{WO}_{3} \cdot 0.33 \mathrm{H}_{2} \mathrm{O}$ sample consisted of agglomerates of fine particles, whereas $\mathrm{WO}_{3}$-A was composed of rectangular-shaped particles. This different morphology suggests that $\mathrm{WO}_{3}$ was formed by a dissolution-recrystallization mechanism under HTT conditions. Higher $\mathrm{T}_{\text {HTT }}$ and longer HTT duration accelerated particle growth of $\mathrm{WO}_{3}$, and the length of the particle of $\mathrm{WO}_{3}$ became longer, which was consistent with the results of XRD. Another feature of $\mathrm{WO}_{3}$ particles observed in the SEM analyses is coagulation of particles by HTT of longer duration. The BET surface area $\left(\mathrm{S}_{\mathrm{BET}}\right)$ of each sample is shown in Table 1. With elevation in $\mathrm{T}_{\mathrm{HTT}}$ and prolongation of HTT time, $\mathrm{S}_{\mathrm{BET}}$ of $\mathrm{WO}_{3}$ decreased due to an increase in the size of primary $\mathrm{WO}_{3}$ particles.

Figure 12 shows the time course of $\mathrm{O}_{2}$ evolution from a suspension of $\mathrm{WO}_{3}-\mathrm{B}$ particles under UV-visible light irradiation. In this system, $\mathrm{O}_{2}$ evolved linearly with irradiation time up to 20 min. The yields of $\mathrm{O}_{2}$ and photodeposited Ag after 20-min irradiation was 23 and $89 \mu \mathrm{mol}$, respectively, and the $\mathrm{Ag} / 4 \mathrm{O}_{2}$ ratio was 0.97 , indicating that $\mathrm{O}_{2}$ evolution accompanying stoichiometric Ag deposition $\left(4 \mathrm{Ag}^{+}+2 \mathrm{H}_{2} \mathrm{O} \rightarrow 4 \mathrm{Ag}+\mathrm{O}_{2}+4 \mathrm{H}^{+}\right)$proceeds efficiently. The rate of $\mathrm{O}_{2}$ evolution, i.e., the slope of the time-course curve, gradually decreased after $20 \mathrm{~min}$. The $\mathrm{pH}$ of the suspension decreased with the above reaction producing $\mathrm{H}^{+}$, and the amount of $\mathrm{Ag}^{+}$adsorbed on photocatalyst particles decreased with lowering of $\mathrm{pH}[24,25]$, which accounts for the decrease in $\mathrm{O}_{2}$ evolution. The activities of the present $\mathrm{WO}_{3}$ samples were evaluated by the yields of $\mathrm{O}_{2}$ and Ag after 20-min irradiation and are listed in Table 1. All $\mathrm{WO}_{3}$ samples, including three commercial ones, tested in this study, exhibited activity, though the tungstite and $\mathrm{WO}_{3} \cdot 0.33 \mathrm{H}_{2} \mathrm{O}$ samples showed negligible activity. Among the $\mathrm{WO}_{3}$ samples listed in Table 1 , the $\mathrm{WO}_{3}$ samples of high crystallinity 
prepared via IE-HTT showed higher activities than those of the commercial $\mathrm{WO}_{3}$ samples; $\mathrm{WO}_{3}-\mathrm{B}$ exhibited the highest activity. It has been pointed out that the crystallinity of $\mathrm{TiO}_{2}$ controls the activity in photocatalytic $\mathrm{O}_{2}$ evolution from an aqueous suspension of $\mathrm{TiO}_{2}[19$, 26]. The above-stated results clearly show that the same strategy of design can be applied to $\mathrm{WO}_{3}$ photocatalyst for $\mathrm{O}_{2}$ evolution. $\quad \mathrm{WO}_{3}-\mathrm{C}$ synthesized with a longer period possessed higher crystallinity and was expected to show higher activity than, for example, that of $\mathrm{WO}_{3}$-B. However, this was not the case. As observed in SEM (Figure 11), $\mathrm{WO}_{3}-\mathrm{C}$ particles, unlike $\mathrm{WO}_{3}$-B particles, were strongly coagulated to give large secondary particles. It is known that grain boundaries of $\mathrm{TiO}_{2}$ particles induce recombination of electron-hole pairs [27]. Coagulation of particles might produce crystal defects, at boundaries of $\mathrm{WO}_{3}$ particles, acting as recombination centers of electron-hole pairs. $\mathrm{WO}_{3}-\mathrm{D}$ prepared from solid $\mathrm{H}_{2} \mathrm{WO}_{4}$ by HTT showed a smaller $\mathrm{O}_{2}$ yield than those of other HTT and commercial $\mathrm{WO}_{3}$ samples. Crystallinity of the $\mathrm{WO}_{3}$ powder might be insufficient for $\mathrm{O}_{2}$ formation, which is supported by its relatively large $\mathrm{S}_{\mathrm{BET}}\left(8.9 \mathrm{~m}^{2} \mathrm{~g}^{-1}\right)$.

Photocatalytic activity was also examined with 2-h photoirradiation at a wavelength of $>$ $420 \mathrm{~nm}$ using a cut-off filter. $\mathrm{WO}_{3}-\mathrm{B}$ gave $12 \mu \mathrm{mol}$ yield of $\mathrm{O}_{2}$ under visible-light irradiation, though the apparent activity was much smaller than that with UV-visible irradiation due to the large decrease in the total number of photons irradiated to $\mathrm{WO}_{3}$ particles. Degussa P-25, one of the most active $\mathrm{TiO}_{2}$ photocatalysts, showed negligible $\mathrm{O}_{2}$ evolution (0.3 $\mu \mathrm{mol})$ due to the larger band gap energy (3.2 eV corresponding to ca. $390 \mathrm{~nm}$ ).

\section{Conclusion}

Anatase and brookite-type $\mathrm{TiO}_{2}$ and $\mathrm{WO}_{3}$ samples were successfully synthesized by solvothermal technique. Physical properties of these semiconductors can be controlled by changing solvothermal condition and post-calcination temperature. These solvothermal 
Kominami et al., Solvothermal Syntheses of Photocatalysts

products exhibited higher or similar activities than commercial active Degussa P-25 in several photocatalytic reaction systems.

\section{Acknowledgement}

This work was partly supported by grants-in-aid from the Ministry of Education, Science, Sports, and Culture of Japan (09750861, 09218202, 09044114, and Priority Areas 417). 


\section{References}

[1] T. Wakanabe, A. Kitamura, E. Kojima, C. Nakayama, K. Hashimoto and A. Fujishima, p. 747, in: Photocatalytic purification and treatment of water and air, eds. D. E. Olis and H. Al-Ekabi, Elsevier, 1993.

[2] M. A. Fox and M. T. Dulay, Chem. Rev. 93 (1993) 341.

[3] M. R. Hoffmann, S. T. Martin, W. Choi and D. W. Bahnemann, Chem. Rev. 95 (1995) 69.

[4] T. Ibusuki and K. Takeuchi, J. Mol. Catal. 88 (1994) 93.

[5] B. Ohtani and S.-i. Nishimoto, J. Phys. Chem. 97 (1993) 920.

[6] M. Kiyama, T. Akita, Y. Tsutsumi and T. Takada, Chem. Lett. 1972, 21.

[7] T. Mitsuhashi and M. Watanabe, Mineralogical Journal 9 (1978) 236.

[8] B. Ohtani, J.-i. Handa, S.-i. Nishimoto and T. Kagiya, Chem. Phys. Lett. 120 (1985) 292.

[9] J. R. Darwent and A. Mills, J. Chem. Soc., Faraday Trans., 278 (1982) 359.

[10] W. Erbs, J. Desilvestro, E. Borgarello and M. Grätzel, J. Phys. Chem. 88 (1984) 4001.

[11] K. Sayama and H. Arakawa, J. Phys. Chem. 97 (1993) 531.

[12] T. Ohno, F. Tanigawa, K. Fujihara, S. Izumi and M. Matsumura, J. Photochem. Photobiol. A: Chem. 118 (1998) 41.

[13] K. Byrappa and M. Yoshimura, Handbook of Hydrothermal Technology, Noyes, 2001.

[14] M. Inoue, K. Kitamura, H. Tanino, H. Nakayama and T. Inui, Clays Clay Miner. 37 (1989) 71.

[15] H. Kominami, M. Kohno and Y. Kera, J. Mater. Chem. 10 (2000) 1151.

[16] B. Ohtani, M. Masuoka, T. Atsumi, S.-i. Nishimoto and T. Kagiya, Chem. Express 3 (1988) 319.

[17] H. Kominami, J.-i. Kato, M. Kohno, Y. Kera and B. Ohtani, Chem. Lett. (1996) 1051.

[18] S.-i. Nishimoto, B. Ohtani and T. Kagiya, J. Chem. Soc., Faraday Trans. 181 (1985) 61. 
[19] H. Kominami, S.-y. Murakami, Y. Kera and B. Ohtani, Catal. Lett. 56 (1998) 125.

[20] JCPDS card No. 21-1272.

[21] JCPDS card No. 29-1360

[22] JCPDS card No. 35-0270

[23] JCPDS card No. 43-1035

[24] B. Ohtani and S.-i. Nishimoto, J. Phys. Chem. 1993, 97, 920.

[25] B. Ohtani, Y. Okugawa, S.-i. Nishimoto and T. Kagiya, J. Phys. Chem. 1987, 91, 3550.

[26] H. Kominami, T. Matsuura, K. Iwai, B. Ohtani, S.-i. Nishimoto and Y. Kera, Chem. Lett., 1995, 693.

[27] P. T. Landsberg, Recombination in Semiconductors, Cambridge University Press, Cambridge (1991), p. 208. 
Figure captions

Figure 1 Reaction apparatus

Figure 2 XRD patterns of (a) $\mathrm{TiO}_{2}$ prepared by the alcohothermal treatment of titanium n-butoxide in 2-butanol at $573 \mathrm{~K}$, and (b), (c), and (d) the samples obtained by calcination of (a) at 823, 973 and $1173 \mathrm{~K}$, respectively.

Figure 3 A TEM photograph of $\mathrm{TiO}_{2}$ prepared by the alcohothermal treatment of titanium n-butoxide in 2-butanol at $573 \mathrm{~K}$

Figure 4 Effect of calcination on surface area and crystallite size of $\mathrm{THyCA}^{-\mathrm{TiO}_{2}}$.

Figure 5 Effect of calcination on the $\mathrm{CO}_{2}$ evolution rate of $\mathrm{THyCA}^{-\mathrm{TiO}_{2}}$ in photocatalytic mineralization of acetic acid.

Figure 6 Effect of calcination on the $\mathrm{H}_{2}$ evolution rate of platinized $\mathrm{THyCA}^{-\mathrm{TiO}_{2}}$ in photocatalytic dehydrogenation of 2-propanol in aqueous suspension.

Figure $7 \quad \mathrm{XRD}$ patterns of (a) $\mathrm{TiO}_{2}$ prepared by the solvothermal treatment of $\mathrm{TiO}(\mathrm{acac})_{2}$ in EG- $\mathrm{H}_{2} \mathrm{O}$ in the presence of sodium acetate at $573 \mathrm{~K}$, and (b), (c), (d), (e) and (f) the samples obtained by calcination of (a) at 623, 823, 973, 1073 and $1173 \mathrm{~K}$, respectively.

Figure 8 Effect of calcination on surface area and crystallite size of brookite-type $\mathrm{TiO}_{2}$.

Figure 9 Effect of calcination on the $\mathrm{H}_{2}$ evolution rate of platinized brookite- $\mathrm{TiO}_{2}$ in photocatalytic dehydrogenation of 2-propanol in aqueous suspension.

Figure 10 XRD patterns of the compounds obtained by HTT of an $\mathrm{H}_{2} \mathrm{WO}_{4}$ solution at (a) $473 \mathrm{~K}$ for $2 \mathrm{~h}$, (b) $523 \mathrm{~K}$ for $2 \mathrm{~h}\left(\mathrm{WO}_{3}-\mathrm{A}\right)$, (c) $573 \mathrm{~K}$ for $2 \mathrm{~h}\left(\mathrm{WO}_{3}-\mathrm{B}\right)$, and (d) $573 \mathrm{~K}$ for 8 $\mathrm{h}\left(\mathrm{WO}_{3}-\mathrm{C}\right)$.

Figure 11 SEM photographs of the compounds whose XRD patterns are shown in Figure 10.

Figure 12 Time course of $\mathrm{O}_{2}$ evolution from $\mathrm{Ag}_{2} \mathrm{SO}_{4}$ in an aqueous suspension of 
Kominami et al., Solvothermal Syntheses of Photocatalysts

$\mathrm{WO}_{3}$-B under UV-visible light irradiation. 


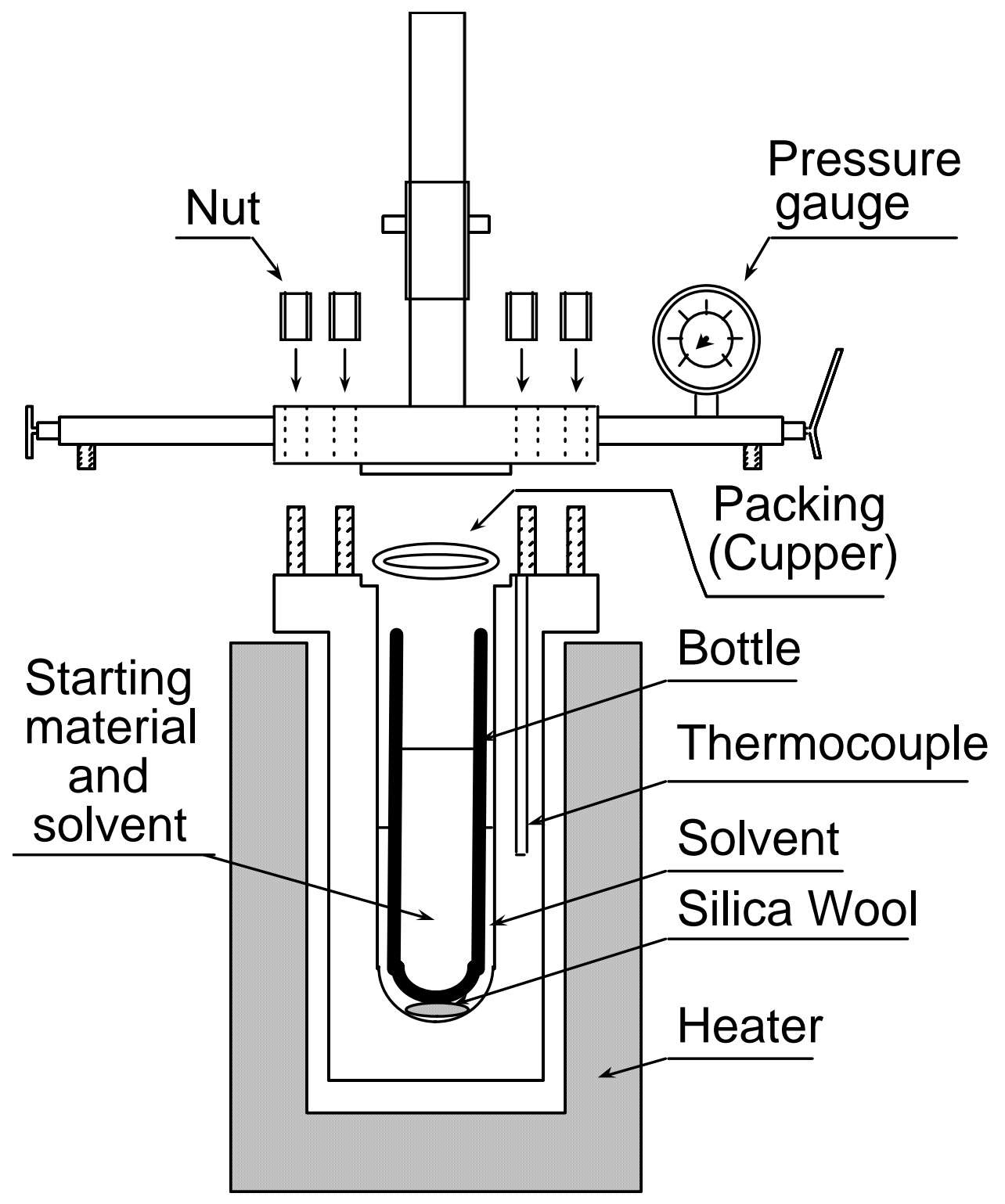

Kominami et al., Fig. 1 


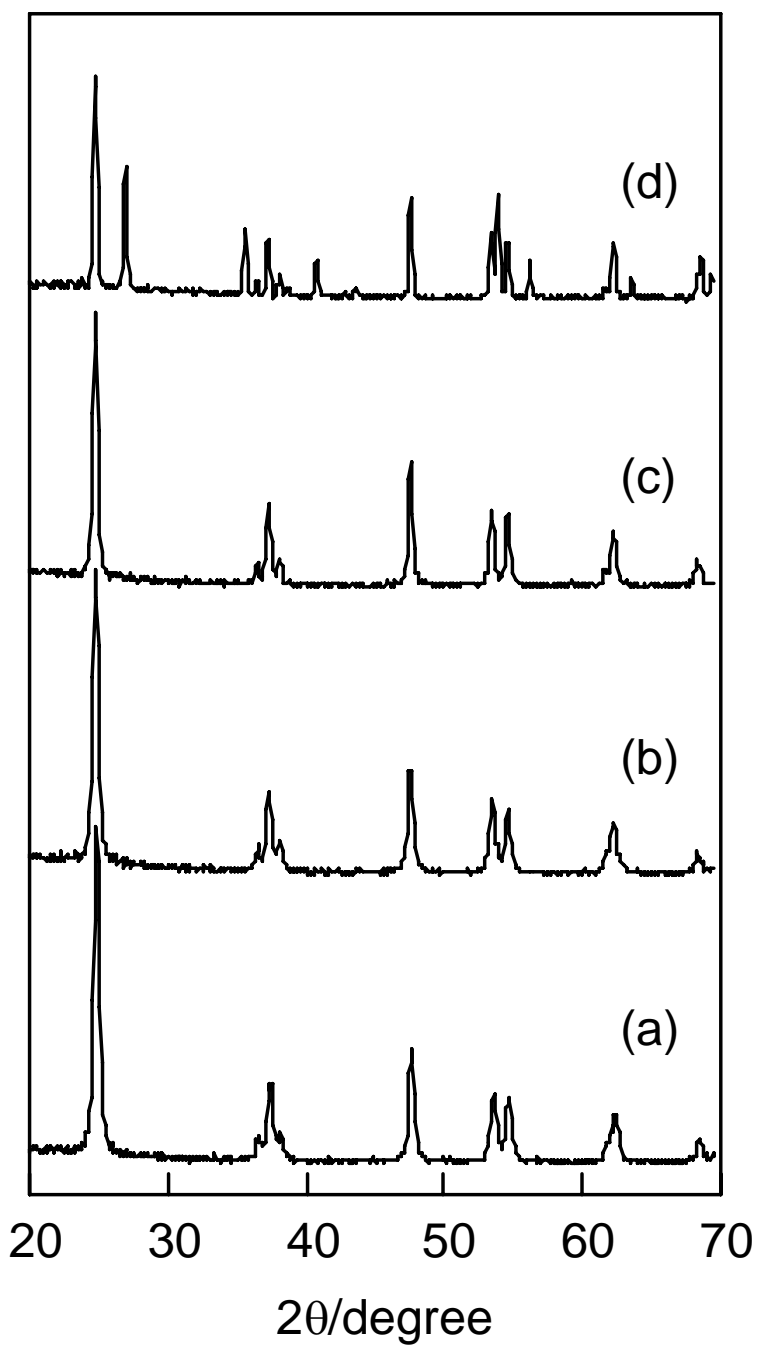

Kominami et al., Fig. 2 


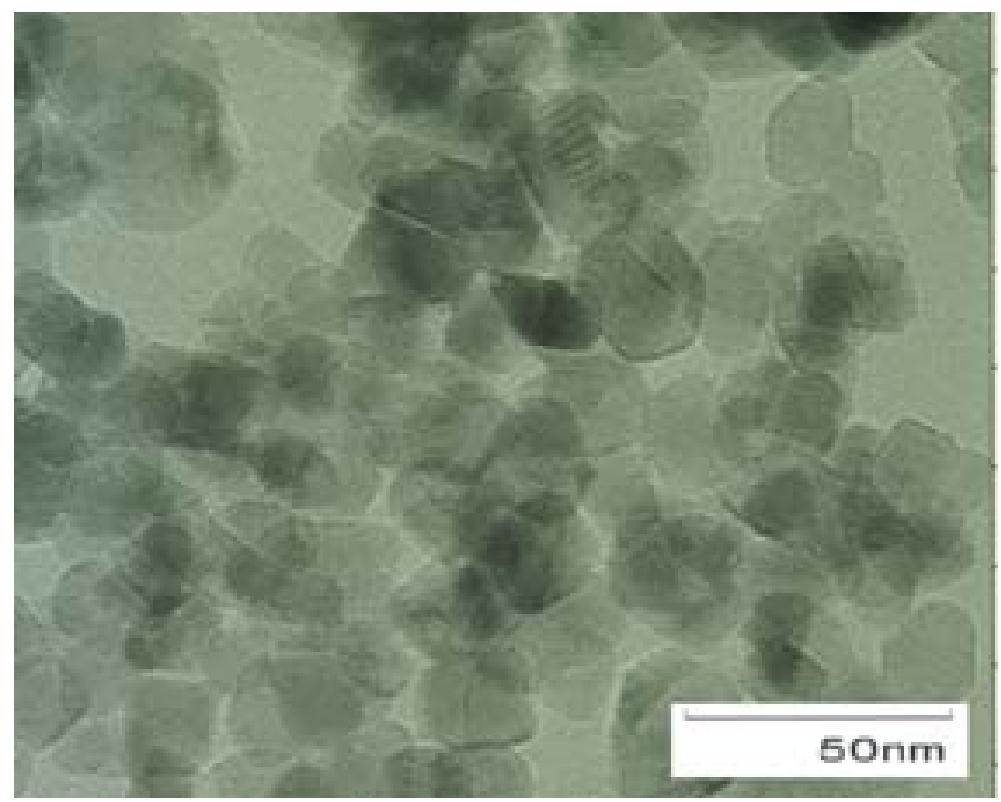

Kominami et al., Fig. 3 


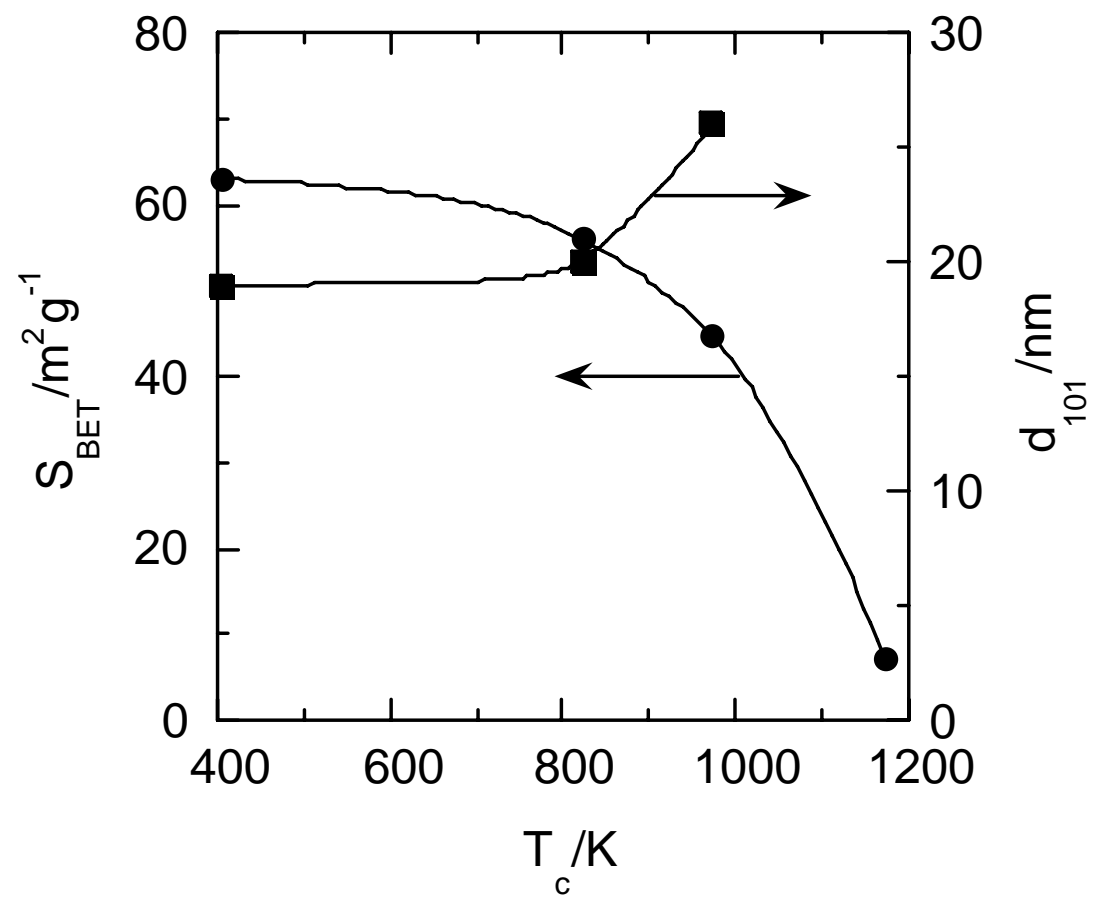

Kominami et al., Fig. 4 


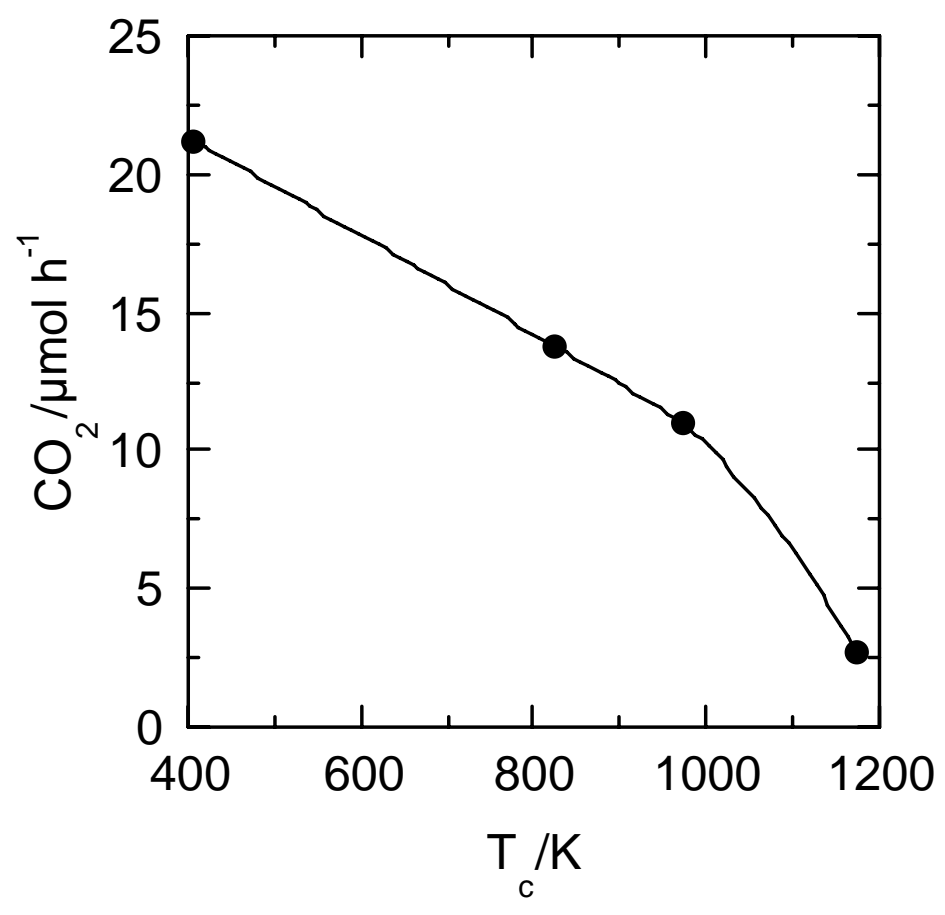

Kominami et al., Fig. 5 


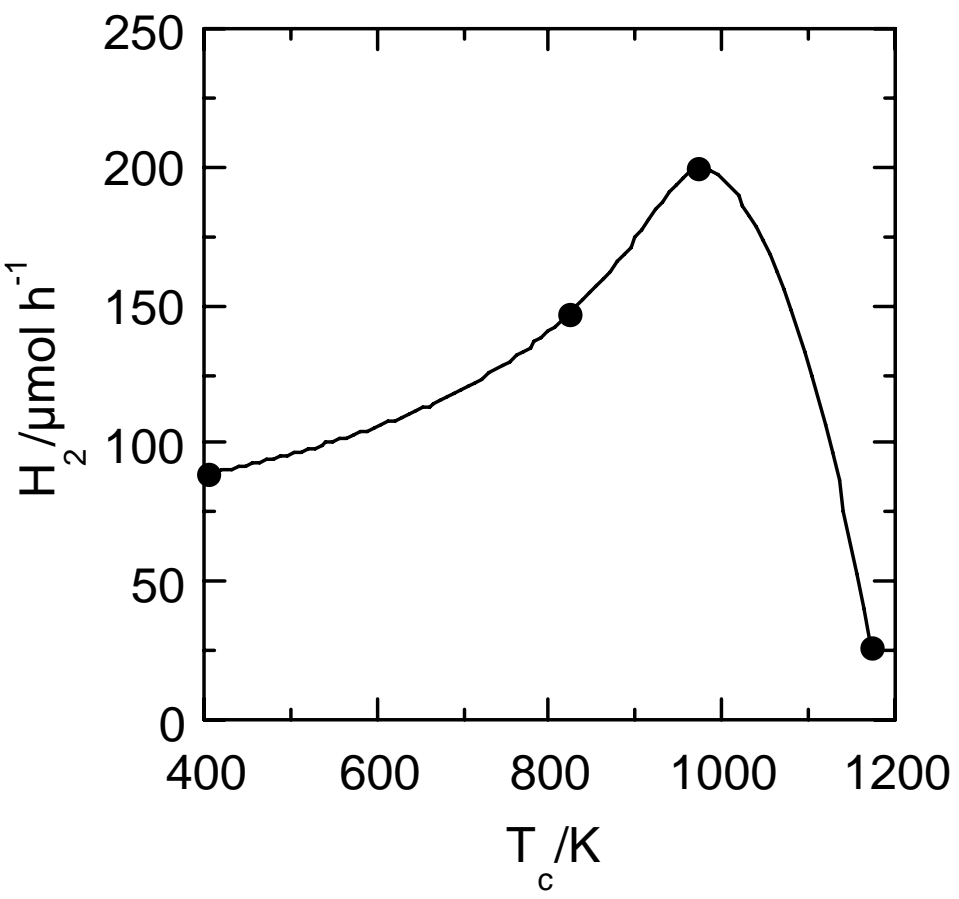

Kominami et al., Fig. 6 


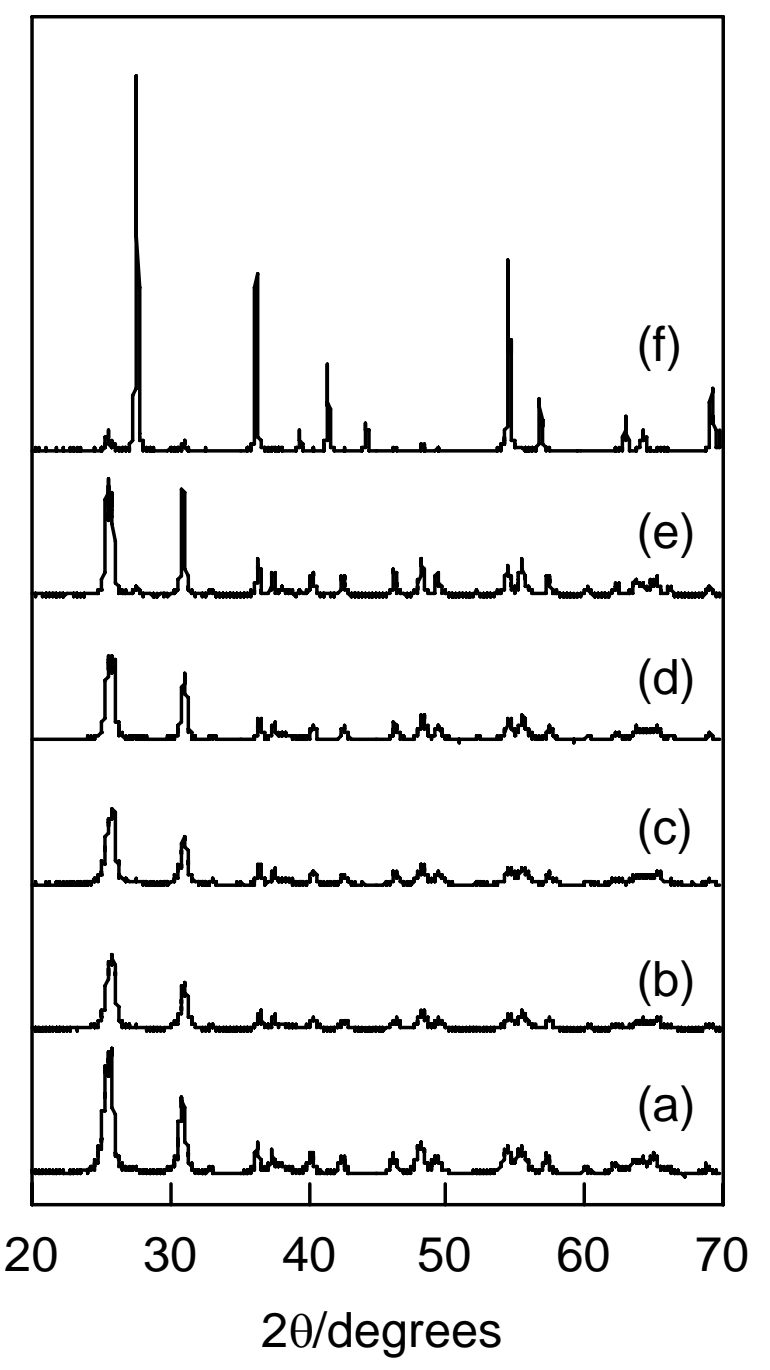

Kominami et al., Fig. 7 


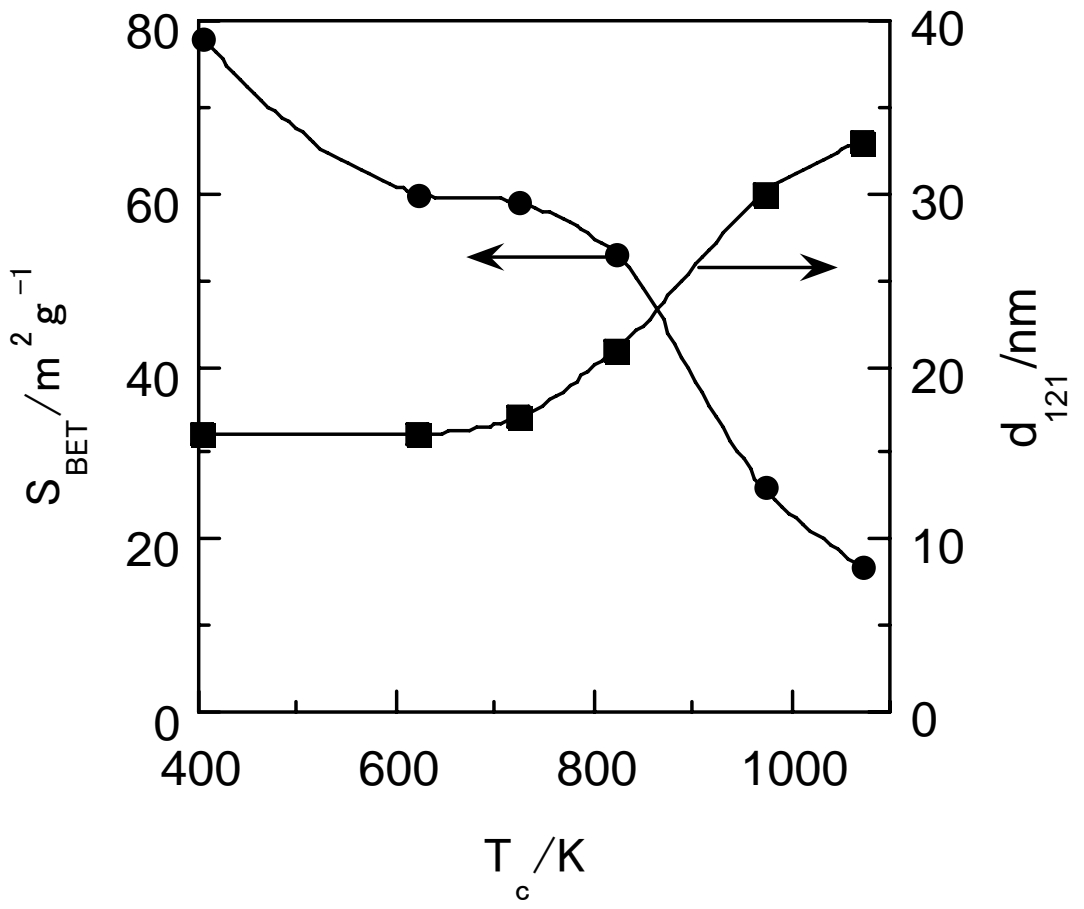

Kominami et al., Fig. 8 


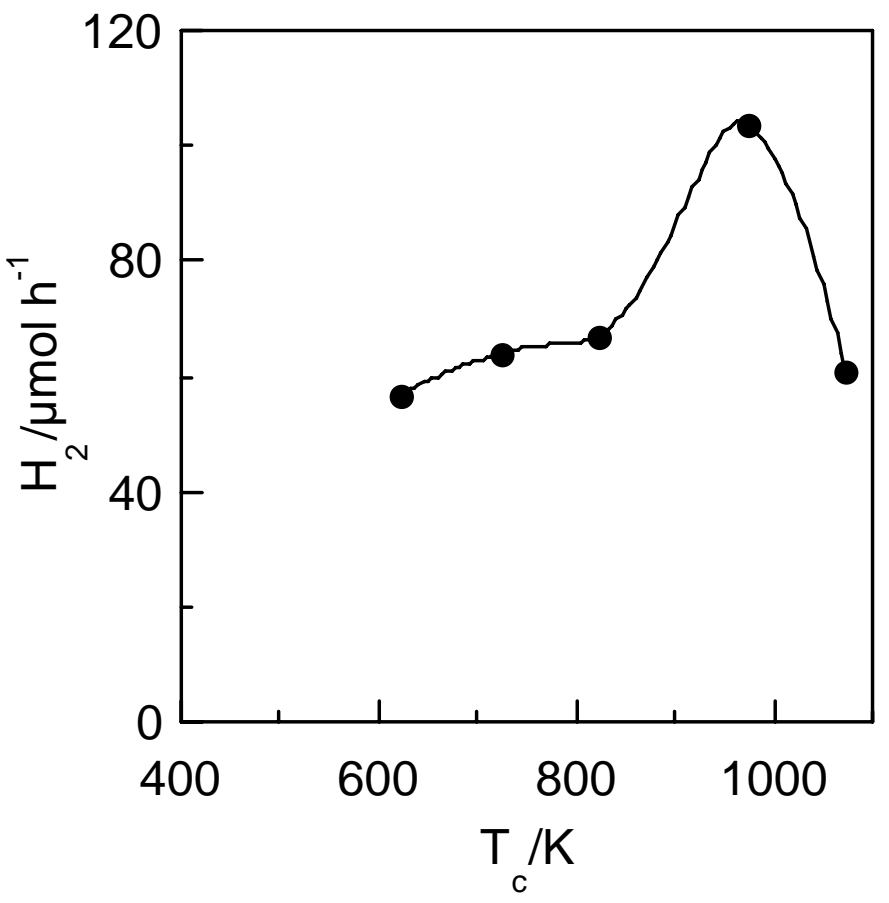

Kominami et al., Fig. 9 


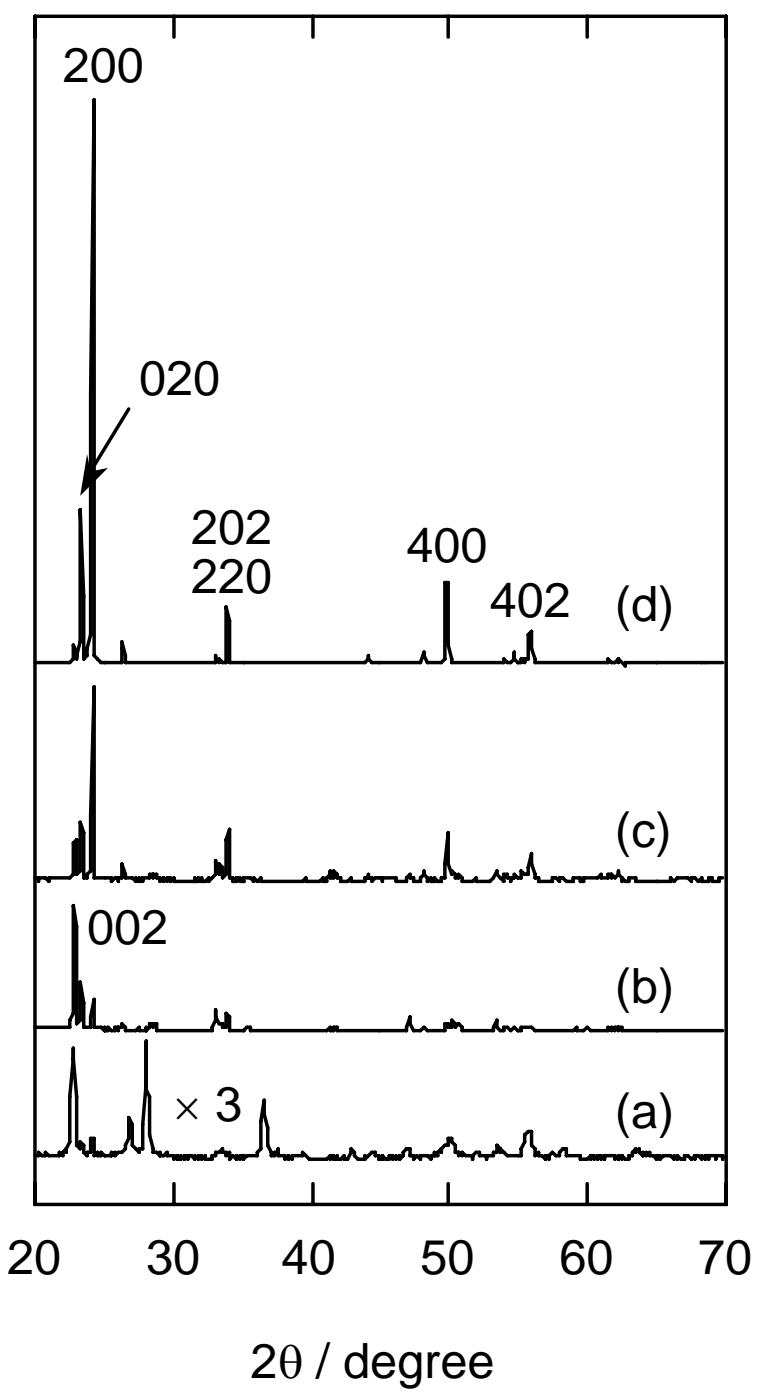

Kominami et al., Fig. 10 


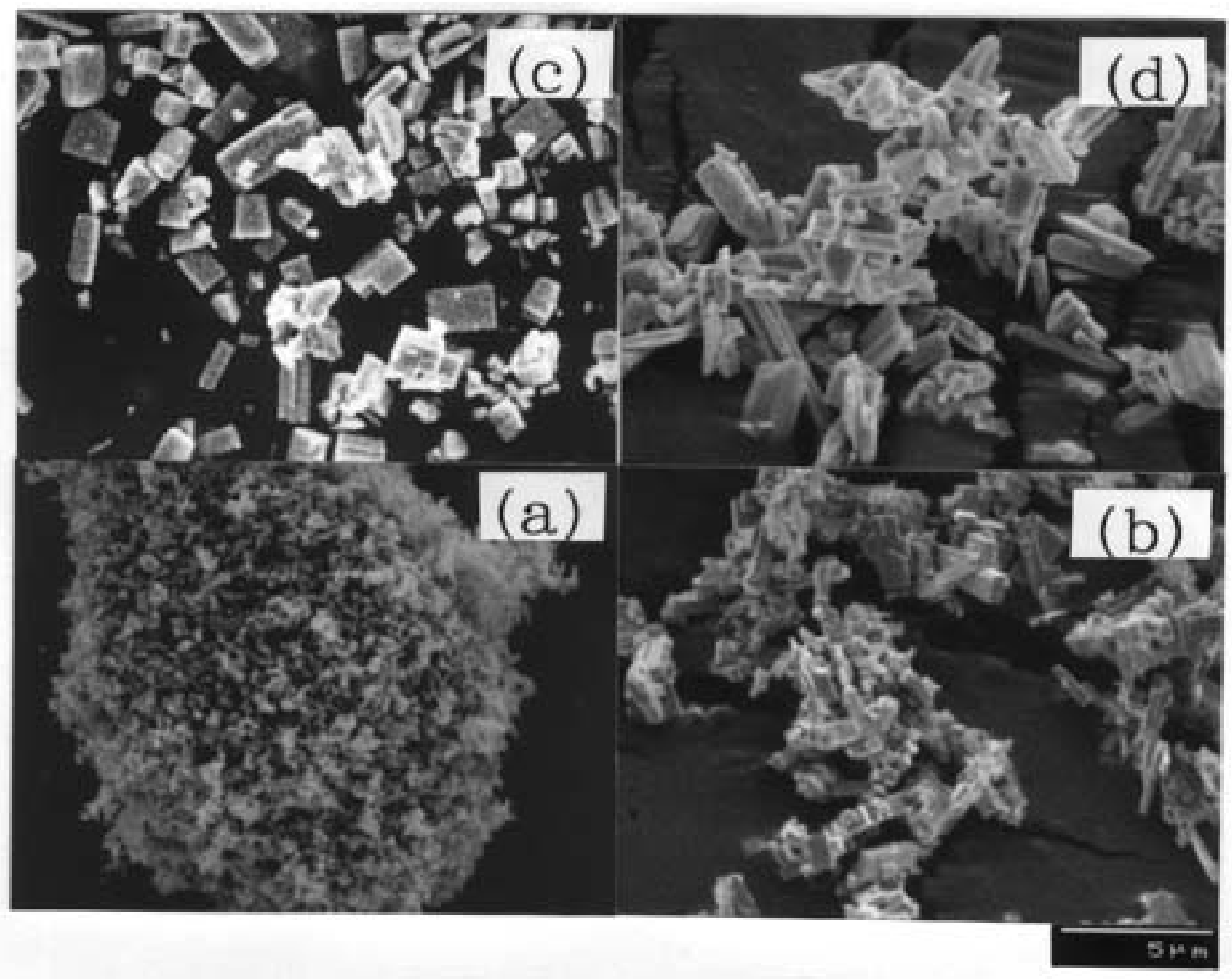

Kominami et al., Fig. 11 


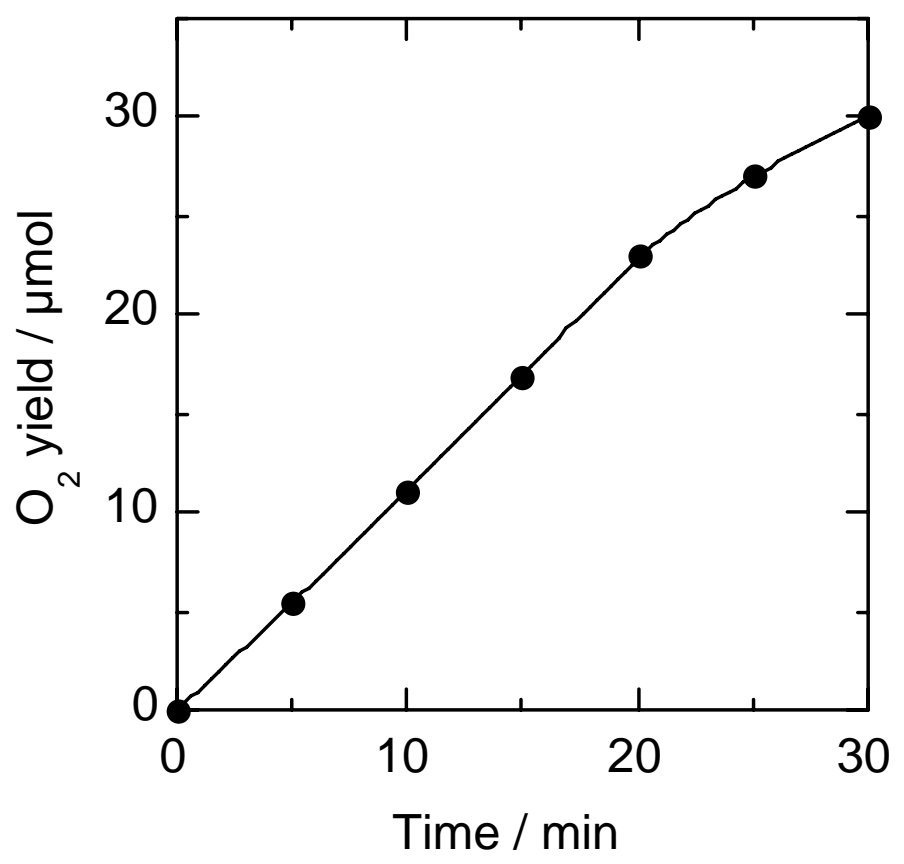

Kominami et al., Fig. 12 


\section{Table 1}

Photocatalytic activity (20-min irradiation) of $\mathrm{HTT}-\mathrm{WO}_{3}$ products prepared from various starting materials

\begin{tabular}{llllccccc}
\hline sample & $\begin{array}{l}\mathrm{H}_{2} \mathrm{WO}_{4} \\
\text { material }\end{array}$ & $\begin{array}{l}\mathrm{T}_{\mathrm{HTT}}{ }^{\mathrm{a}} \\
/ \mathrm{K}\end{array}$ & $\begin{array}{l}\mathrm{t}_{\mathrm{HTT}}{ }^{\mathrm{a}} \\
/ \mathrm{h}\end{array}$ & phase & $\begin{array}{l}\mathrm{S}_{\mathrm{BET}} \\
/ \mathrm{m}^{2} \mathrm{~g}^{-1}\end{array}$ & $\begin{array}{l}\mathrm{O}_{2} \\
/ \mu \text { mol }\end{array}$ & $\begin{array}{l}\mathrm{Ag} \\
/ \mu \mathrm{mol}\end{array}$ & $\begin{array}{l}\mathrm{Ag} \\
/ 4 \mathrm{O}_{2}\end{array}$ \\
\hline $\mathrm{WO}_{3} \cdot 0.33 \mathrm{H}_{2} \mathrm{O}$ & solution $^{\mathrm{b}}$ & 473 & 2 & orthorhombic & 18 & 1.9 & 8.2 & 1.1 \\
$\mathrm{WO}_{3}-\mathrm{A}$ & solution $^{\mathrm{b}}$ & 523 & 2 & monoclinic & 14 & 9.6 & 36 & 0.94 \\
$\mathrm{WO}_{3}-\mathrm{B}$ & solution $^{\mathrm{b}}$ & 573 & 2 & monoclinic & 1.7 & 23 & 89 & 0.97 \\
$\mathrm{WO}_{3}-\mathrm{C}$ & solution $^{\mathrm{b}}$ & 573 & 8 & monoclinic & 0.6 & 15 & 58 & 0.97 \\
$\mathrm{WO}_{3}-\mathrm{D}$ & solid $^{\mathrm{c}}$ & 573 & 2 & monoclinic & 8.9 & 3.0 & 13 & 1.1 \\
$\mathrm{WO}_{3}-\mathrm{E}^{\mathrm{d}}$ & & & & monoclinic & 3.0 & 11 & 47 & 1.1 \\
$\mathrm{WO}_{3}-\mathrm{F}^{\mathrm{e}}$ & & & & monoclinic & 3.1 & 9.8 & 41 & 1.0 \\
$\mathrm{WO}_{3}-\mathrm{G}^{\mathrm{f}}$ & & & & monoclinic & 5.0 & 6.5 & 25 & 0.96 \\
$\left(\mathrm{P}-25 \mathrm{TiO}_{2}\right)^{\mathrm{g}}$ & & & & anatase, rutile & 50 & 4.3 & 19 & 1.1 \\
\hline
\end{tabular}

${ }^{\mathrm{a}}$ Hydrothermal treatment was carried out at $\mathrm{T}_{\mathrm{HTT}}$ for $\mathrm{t}_{\mathrm{HTT}}$.

${ }^{\mathrm{b}} 0.19 \mathrm{~mol} \mathrm{dm}^{-3}, 75 \mathrm{~cm}^{3}$

'Supplied as tungstic acid from Kanto Chemicals.

${ }^{\mathrm{d}}$ High Purity Chemicals (99.99\% purity).

${ }^{\mathrm{e}}$ Kishida Chemicals (99.9\% purity).

${ }^{\mathrm{f}}$ Kanto Chemicals (99.5\% purity).

${ }^{\mathrm{g}}$ Degussa. 